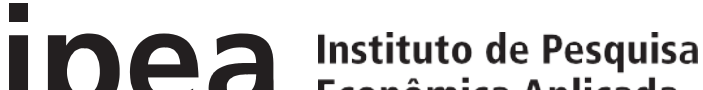 Econômica Aplicada
}

Título do capítulo

Autores(as)

DOI

Título do livro

Organizadores(as)

Volume

\section{Série}

Cidade

Editora

Ano

Edição

ISBN

DOI
CAPÍTULO 1

INTRODUÇÃO: UMA NARRATIVA PARA OS MOVIMENTOS ATUAIS

DA INDÚSTRIA NO TERRITÓRIO

Aristides Monteiro Neto

https://dx.doi.org/10.38116/978-65-5635-020-2/cap1

BRASIL, BRASIS: RECONFIGURAÇÕES TERRITORIAIS DA INDÚSTRIA NO SÉCULO XXI

Aristides Monteiro Neto

Brasilia

Ipea

2021

$1^{1}$

978-65-5635-020-2

https://dx.doi.org/10.38116/978-65-5635-020-2 


\title{
INTRODUÇÃO: UMA NARRATIVA PARA OS MOVIMENTOS ATUAIS DA INDÚSTRIA NO TERRITÓRIO
}

\author{
Aristides Monteiro Neto ${ }^{1}$
}

A discussão empreendida nos capítulos que compõem este livro foi amplamente motivada pela agenda de trabalho conjunto entre Ipea e Ministério do Desenvolvimento Regional (MDR) - ex-ministério da Integração Nacional. O envolvimento com esta parceria institucional instigou a elaboração de diagnósticos de dinâmicas territoriais recentes, tanto dos seus aspectos demográficos, econômicos e ambientais, como das avaliações de instrumentos e instituições da política regional brasileira.

No rol das preocupaçóes do livro, localiza-se a centralidade da atividade industrial. Esta tem sido fundamental nas estratégias de desenvolvimento regional perseguidas desde o fim dos anos 1950 até o presente. Estudos acadêmicos e documentos de governo são abundantes na investigação do papel da indústria nas transformaçôes territoriais do país. Foi a indústria que acelerou o diferencial de níveis de desenvolvimento das diversas macrorregióes nacionais produzindo, desse modo, uma trajetória de disparidades regionais bem diferente da predominante na economia colonial brasileira.

Transcorrido um longo período de expansão e auge da indústria entre 1930 e 1980, a situação passou a mudar, notando-se cada vez mais uma flagrante reduçáo da participaçáo da indústria na economia nacional. Desde os anos 1990, pelo menos, este setor vem sofrendo de perda de competitividade, apresenta reconhecida incapacidade para a modernização tecnológica, sua produtividade média do trabalho tem crescido a taxas muito baixas, acompanhadas de enfraquecimento dos elos das cadeias produtivas.

Por sua importância para a questão regional, o quadro de enfraquecimento e regressão da indústria apresenta enorme interesse de pesquisa. As disparidades regionais aumentaram ou, pelo contrário, foram reduzidas neste contexto de fragilidade produtiva? A perda de relevância da indústria tem sido superada por algum outro vetor de crescimento com robustez para garantir a elevação sustentada da renda per capita nacional? Como tem evoluído a integração do mercado nacional - suas relaçôes intersetoriais e inter-regionais - sem a indústria como motor do crescimento e dos encadeamentos para frente e para trás nas diversas cadeias produtivas?

1. Técnico de planejamento e pesquisa na Diretoria de Estudos e Políticas Regionais, Urbanas e Ambientais (Dirur) do Ipea e organizador deste livro.E-mail: <aristides.monteiro@ipea.gov.br>. 
Os capítulos que compóem este livro tratam desses temas e têm como objetivo contribuir para o debate sobre as possibilidades colocadas hoje na economia brasileira para a condução de um vetor ou de uma estratégia de desenvolvimento regional temporalmente sustentada. As discussóes são organizadas em dois grandes eixos analíticos, os quais estão expressos nos capítulos de introdução e de referências analíticas e conceituais e, posteriormente, nos capítulos de 3 a 11 que compóem as três partes em que se estrutura a investigação. Por fim, o capítulo 12 faz as conclusôes finais.

De início, explicitamos a arquitetura que organiza o conjunto dos capítulos nesta Introdução. Daí partimos para o capítulo 2 de referências conceituais, Induistria e território no Brasil: debates, evidências e hipóteses para uma análise contemporânea, no qual são apresentados os termos do debate e os seus objetivos gerais e específicos. Norteia o trabalho a ideia de mudança estrutural em convergência com as discussóes dos clássicos da teoria do desenvolvimento, em que a transformação estrutural de uma dada economia nacional ou regional seria alcançada por meio da implantação de atividades produtivas de maior produtividade, maior geraçáo de valor adicionado e maiores salários (geralmente, na indústria) e redução relativa da relevância de setores de baixa produtividade e valor agregado (tradicionalmente, na agricultura). A crise atual da indústria brasileira representa o fim e a exaustão de uma estratégia de mudança estrutural iniciada na década de 1930? Está em curso algum outro tipo de mudança estrutural que parte da indústria em direçáo a outras atividades de maior produtividade? Ou, pelo contrário, a economia brasileira se encontra em estágio de anomia estrutural em que seu parque produtivo náo se renova - ou o faz lentamente - nem se coloca no horizonte próximo a existência de um vetor de ampliação da renda per capita e da competitividade nacional?

O capítulo 2, vai além da mudança estrutural e organiza, de um lado, os termos da discussão teórica prevalecente nos estudos do desenvolvimento regional relacionados com as ideias de "integração do mercado nacional", "desconcentração concentrada" e heterogeneidade do desenvolvimento. De outro lado, visando ao esclarecimento dos fenômenos que se expressam no âmbito da atividade industrial, realiza uma incursão detalhada da literatura a respeito de certos temas, como desindustrialização, perda de densidade produtiva, tipologias de setores industriais com base no fator competitivo predominante, especialização em atividades de baixo conteúdo tecnológico e geradores de baixo encadeamento setorial.

A execução do processo investigativo se dá de duas maneiras ou recortes territoriais. A parte I, chamada de Reestruturação produtiva e desconcentração territorial da indústria: as escalas macrorregional e estadual, tem a escala territorial macrorregional e estadual como referência - no capítulo 3, intitulado Desconcentração territorial e reestruturaçâo regressiva: padróes e ritmos - e, a partir de então, se centra 
no comportamento da indústria (extrativa e de transformação) com dados de valor da transformação industrial (VTI) e do valor adicionado bruto (VAB) da indústria para os anos 1996, 2000, 2005, 2010 e 2015. As principais transformaçóes da indústria e seus ramos de atividade são apontadas para o período considerado e esclarecem a existência do baixo crescimento dos ramos industriais relacionados a atividades sofisticadas e de alto valor agregado. A mudança estrutural em curso consolida-se como um tipo regressivo em que os grupos de indústria indutores de progresso técnico e aumento da produtividade estáo perdendo espaço para atividades cujos diferenciais competitivos são os recursos naturais e a mão de obra barata.

Os capítulos 4, Transformaçôes recentes da indústria no Sudeste: evidências da dinâmica produtiva e territorial entre 1996 e 2015, de Raphael de Oliveira Silva; e 5, A orientaçáo locacional da indústria paulista no território brasileiro entre 1995 e 2015: desconcentração concentrada e reforço do polígono industrial, de Danilo Severian, trazem importantes desdobramentos de questóes abertas no capítulo $3 \mathrm{e}$ discutem as transformaçóes na economia central do capitalismo brasileiro e como aquelas afetam os processos de desconcentração produtiva regional. Em particular, no estudo realizado por Raphael de Oliveira Silva sobre o quadro da indústria da regiâo Sudeste, são esmiuçadas evidências das transformaçóes da economia regional de maior peso na dinâmica nacional brasileira. Revela-se que o centro das atividades de maior capacidade competitiva e de progresso técnico continua sendo a economia paulista e que parte mais relevante da desconcentraçáo verificada nesta refere-se ao movimento de saída de atividades da Região Metropolitana (RM) de São Paulo em direçáo ao interior do próprio estado. Por seu turno, o crescimento industrial observado nas economias fluminense (Rio de Janeiro) e mineira (Minas Gerais) tem forte componente de atividades ligadas a atividades extrativas ou processadores de recursos naturais (petróleo e minério de ferro).

Por sua vez, o capítulo 5, de Danilo Severian, ocupa-se em apresentar a forma como a economia paulista expressa o seu comando sobre o restante da economia nacional, o estudo utiliza uma importante base de dados de emprego industrial a Relação Anual de Informações Sociais (Rais), do Ministério do Trabalho e Emprego (MTE) - para observar que as decisóes de investimento das empresas com matrizes na RM de São Paulo preferencialmente definem a expansão de empregos das suas filiais de São Paulo para o interior do próprio estado e, adicionalmente, nesta ordem, para os estados da regiáo Sul e, somente depois, para as regiôes Nordeste, Centro-Oeste e Norte do país. Estes resultados expressam comportamentos empresariais de grande relevância para os estudos das economias de aglomeração: confirmam a manutenção de um quadro estrutural de dificuldades para a consolidação de um vetor de desconcentração industrial que favoreça mais amplamente as regióes do país com menor renda per capita e ainda pouco industrializadas. 
Os três capítulos se completam para fornecer elementos explicativos que corroboram que o movimento de desconcentração regional da indústria, iniciado na década de 1970, não foi estancado e ainda está em curso. Sua natureza, entretanto, é de desconcentração limitada, em termos de velocidade e ritmo com que se manifesta, e também restrita a determinados ramos de atividades. E, mais importante, no termo cunhado por Wilson Cano, o processo atual de desconcentração é "espúrio", ou seja, ao contrário da desconcentração ocorrida entre 1970 e 1985 , que se manifestou simultaneamente com a expansão setorial na região "centro" e nas "periferias", o processo em curso se realiza por desfalecimento da indústria como motor de crescimento e diminuição de sua presença na economia nacional.

A segunda parte do livro, nomeada de Território das aglomeraçóes industriais: a escala microrregional, tem seus capítulos orientados para a investigação em escala territorial das microrregióes geográficas (MRGs), do Instituto Brasileiro de Geografia e Estatística (IBGE), e, mais particularmente, pelo uso da tipologia de aglomeração industrial relevante (AIR), que é a MRG definida por conter 10 mil ou mais empregos industriais formais. A ampliação da escala territorial tem o propósito de se aproximar da diversidade e da heterogeneidade de processos de crescimento e involução de subáreas específicas. Mapear a presença de territórios desiguais, heterogêneos e com potencialidades distintas, bem como apontar suas características evolutivas são objetivos que se prestam a qualificar as estratégias e o alcance dos instrumentos da política regional brasileira.

O primeiro capítulo da parte II, o capítulo 6, intitulado Um novo mapa da indústria no Brasil, de 1995 a 2015, traz os conceitos e usos da tipologia AIRs na literatura especializada sobre desenvolvimento regional no Brasil. $\mathrm{O}$ foco da análise se volta para o emprego industrial como uma variável proxy ou com características próprias para espelhar a dinâmica da atividade industrial no território. $\mathrm{O}$ banco de dados utilizado é a Rais/MTE para os anos 1995, 2000, 2005, 2010, 2015 - periodização que será estendida para incluir os anos 2016, 2017 e 2018 na parte III.

O quadro evolutivo do número de AIRs e da quantidade de empregos e estabelecimentos industriais a elas associadas é devidamente apresentado. Sua expressão territorial é esmiuçada e comparada com o mesmo quadro inicialmente construído por Diniz e Crocco (1996) para a dinâmica de crescimento de grupos de aglomeraçóes previamente escolhidas durante os anos 1970, 1980 e 1991. Ficou evidente no contraste realizado que, ao lado da continuidade da expansão do território da atividade industrial - que passou de 85 AIRs em 1995 para 160 em 2015 -, o ritmo de expansão do emprego industrial foi bastante alterado. Se entre 1970 e 1991, conforme os autores citados, o crescimento do emprego nas AIRs foi mais elevado (3,5\% ao ano - a.a.), no período 1995-2015, a pesquisa atual revelou que sua evolução foi mais modesta, 1,9\% a.a. Contudo, na fase recente, constatou-se a existência de aglomeraçôes com perdas absolutas de emprego industrial, comportamento não 
observado nas décadas anteriores. Também se verificou que um número relevante significativo de AIRs de pequeno tamanho de empregos (pouco acima de $10 \mathrm{mil}$ e náo ultrapassando os $20 \mathrm{mil}$ ) apresentou taxas superiores a quatro vezes a média nacional, isto é, a dispersão em torno da média foi muito maior no período recente que no passado. A evolução da atividade industrial se tornou menos intensa (menor média) e mais volátil (maior dispersão ou variância).

A investigação das AIRs ganha momentum no capítulo 7, $O$ território das atividades industriais no Brasil: a força das economias de aglomeração e urbanização, ao intensificar o mapeamento das AIRs pelo recorte das Grandes Regióes clássicas do país e trazer evidências de focos de mudanças mais recorrentes em cada uma delas. O propósito é apresentar de maneira mais veemente a utilidade da tipologia AIR para a mensuração e identificação de avanços e recuos nos esforços de expansão de atividades econômicas em cada região. O estudo aponta ainda, sempre que possível, a evolução de aglomeraçóes mais expressivas em cada contexto regional recente. Por exemplo, esclarece que não somente as AIRs consolidadas tiveram seu emprego industrial expandido na faixa litorânea (metrópoles e capitais dos estados) do Nordeste, como também as novas aglomeraçóes no entorno das já existentes, mas que não eram "relevantes", passaram a ser e a consolidar, por proximidade, uma área ou campo aglomerativo superior. Outro caso de destaque, referente à dinâmica na regiâa Centro-Oeste, foi a constatação do campo aglomerativo formado pelas AIRs de Goiânia-Anápolis (Goiás) com Brasília (Distrito Federal). As três AIRs respondem, conjuntamente, por uma aglomeração urbana potencial de quase 6 milhões de habitantes e de 152,2 mil empregos industriais em 2015.

Depois de apresentar o novo mapa territorial do emprego industrial do período recente e revelar seus mais expressivos pontos de dinâmica (capítulos 6 e 7), discutimos longamente, no capítulo 8, intitulado Aglomeraçôes industriais relevantes e potenciais: novas dinâmicas territoriais brasileiras, uma importante implicação da territorialização permitida pelas AIRs e que tem a ver com o debate sobre a existência e força do "polígono da desconcentração concentrada" proposto por Diniz (1993). Esta hipótese volta a ser discutida à luz dos novos dados e das transformaçóes qualitativas presentes na dinâmica da atividade industrial em curso. Foi construído um percurso para o debate da hipótese em que se considerou a existência de um "polígono restrito", composto pelos mesmos vértices estabelecidos por Diniz (1993) e definidos pelos pontos que ligam as AIRs de Belo Horizonte-São Paulo-Curitiba-Florianópolis-Porto Alegre e retornam por Maringá-Uberlândia e se encontram novamente com Belo Horizonte. Neste polígono ficaram de fora as AIRs do Rio de Janeiro e do Espírito Santo, bem como as aglomeraçôes acima da RM de Belo Horizonte. Por meio das estimativas do VAB da atividade industrial, como proxy, da atividade destas AIRs, apontamos que o VAB gerado neste polígono corresponde a 66,3\% do total nacional das AIRs em 2015 (o percentual foi de 74,3\% em 2000). 
Em outro caminho analítico, consideramos a existência de um "polígono ampliado", o qual corresponde a todas as AIRs existentes nas regióes Sudeste e Sul do país no período recente. O que significa dizer que este "polígono ampliado" pode ser entendido como todo o território da Grande Regiáo Sudeste-Sul, inclusive Rio de Janeiro e Espírito Santo que náo entraram no polígono restrito, e campo preferencial da atividade industrial no país. É claro que, nesta versão ampliada, a participaçáo do polígono aumenta ainda mais e se torna um atrator mais poderoso de empreendimentos industriais, contribuindo para o reforço de um vetor da concentração industrial e não o contrário: a concentração produtiva da indústria e a força das economias de aglomeração são mais fortes no recorte do "polígono ampliado", o qual teve 85,1\% do VAB das AIRs nacionais em 2000 e passou a 78,0\% em 2015. Em ambos os casos, isto é, nos dois tipos de polígonos (restrito e ampliado), a força do território das aglomeraçóes das regiôes Sudeste e Sul permanece muito expressiva. Se é forçoso constatar a existência do vetor de desconcentração que se afirma pela expansão da presença de AIRs nas regióes Norte, Nordeste e Centro-Oeste, este se expande morosamente.

Para além do recorte das AIRs, o estudo também investigou o quadro de territórios com nível de emprego industrial mais reduzido e abaixo das 10 mil unidades. Estas aglomeraçóes foram denominadas de aglomeraçóes industriais potenciais (AIPs) do tipo I (com empregos industriais entre 5 mil e 9.999 unidades) e do tipo II (com empregos entre 1 mil e 4.999 unidades). Este reforço revelou dinâmicas industriais de grande proveito para a atuação da política regional. Nas regióes Norte e Nordeste, por exemplo, registrou-se um número elevado de AIPs do tipo II, de pequeno tamanho de empregos e, portanto, com maior fragilidade quanto ao seu potencial de competitividade.

Iniciamos a parte III, Indústria e território: reconfiguração no contexto da crise 2015-2018, cujo objetivo é atualizar temporalmente os estudos precedentes com a incorporaçáo de dados para os anos pós-2015, oferecendo assim uma visão dos efeitos da crise econômica de 2015 a 2018 sobre a trajetória estrutural estabelecida até aquele momento. São três capítulos que compóem esta seção e cada um deles traz, além da atualização temporal, uma contribuição singular para o reforço das evidências sobre as limitaçóes do processo de desconcentração atual.

No capítulo 9, intitulado Distribuição territorial dos desembolsos do BNDES para a industria e a infraestrutura entre 2000 e 2018, elaborado por Raphael de Oliveira Silva em colaboração com a economista Mabel Diz Marques, da Universidade Federal da Bahia (UFBA), examinou-se o comportamento dos desembolsos do BNDES para a indústria de transformação e infraestrutura ao longo do período 2000-2018. Nesse capítulo, os autores tiveram como propósito mapear e avaliar se a atuação deste importante banco público de financiamento do desenvolvimento 
contribui para reforçar e reiterar a concentraçáo regional da atividade produtiva ou, pelo contrário, se ela pode se orientar para a criação de atividades que beneficiam regióes-alvo de políticas regionais no país. Significativos avanços foram identificados e relacionados com um volume relevante de recursos para aglomeraçóes industriais ou MRGs nas regióes Nordeste, Norte e Centro-Oeste. O aporte para as regiốes menos desenvolvidas é relativamente mais significativo na infraestrutura que na indústria. Isso pode ser explicado pelo fato de que muitos dos investimentos foram destinados, entre outros, para empreendimentos de hidrelétricas (regiáo Norte) e usinas eólicas (Nordeste), infraestruturas que aumentam a capacidade regional de oferta de energia para o sistema nacional. No caso dos desembolsos da indústria, a demanda por recursos tende a ser mais ligada ao tamanho e à escala do empreendimento, sendo estes maiores nas regióes Sudeste e Sul. O estudo, ao realizar um perfil territorial dos desembolsos em MRGs, faz um mapeamento exaustivo da atuação do banco e pontifica que há espaço (e necessidade) para uma atuação mais incisiva desta instituição financeira pública para apoiar estratégias mais ousadas de desconcentração de atividades produtivas.

No capítulo 10, Comportamento territorial da indústria no periodo 2010-2018: auge e refluxo das aglomeraçóes industriais relevantes e potenciais, Danilo Severian joga luz sobre o período 2010-2018, o qual cobre o auge e o declínio (crise) da trajetória de recuperação da atividade industrial nas AIRs. Duas contribuiçôes estão registradas neste estudo: a investigação sobre as tendências de desconcentração nas economias estaduais pela observação do papel exercido pela atividade industrial nas AIRs que compóem as RMs versus as do resto do estado; e a observaçáo da indústria a partir da tipologia de intensidade tecnológica (nas categorias alta, média-alta, média-baixa e baixa). O essencial das conclusôes está na confirmação da fragilização estrutural da indústria pela expansão dos grupos de atividade de média-baixa e baixa intensidade tecnológica na matriz produtiva nacional. Resultados inteiramente convergentes com os achados observados no capítulo 3 de que os grupos de indústria ligados a intensidade de mão de obra e a recursos naturais ganharam relevo no período. Adicionalmente, o autor explora elementos da escala de tamanhos prevalecentes na indústria brasileira. As grandes empresas (com quinhentos ou mais empregados) responderam, em 2018, por 1,8\% do número de empresas, com 34,7\% do pessoal ocupado e com $54,3 \%$ do VTI. Por sua vez, as pequenas empresas (com empregos variando de 5 a 29 unidades) representaram nesse mesmo ano 79,1\% do número de empresas, 22,0\% do emprego formal e 9,7\% do VTI.

De maneira a apresentar os movimentos da desconcentração e da dinâmica dos empregos industriais na fase mais recente, caracterizada por um quadro recessivo na economia brasileira no período 2015-2018, esforço investigativo foi ampliado com novos dados e consolidado no capítulo 11, A dinâmica territorial do emprego das aglomeraçóes industriais na crise econômica recente (2015-2018). 
O seu objetivo, fundamentalmente, é apontar como a situação pós-2015 afeta a trajetória de desconcentração produtiva descrita nos capítulos anteriores. Quatro pontos essenciais podem ser ressaltados sobre os efeitos da recessão: i) há uma forte queda da atividade industrial (medida pelo VTI), fazendo-a voltar ao seu nível de 1995; ii) visto a partir da composição regional do VTI, não houve retrocesso no processo de desconcentração produtiva; iii) visto pela dinâmica das AIRs, houve uma pequena redução no números de AIRs (de 160 para 157), com uma perda total de 452 mil empregos industriais entre 2015 e 2018 (ponta a ponta); e iv) perderam mais empregos as AIRs mais consolidadas e com maior número de empregos nas metrópoles nacionais e regionais, capitais dos estados e aglomeraçóes do interior do estado de Sáo Paulo. Em suma, o quadro estrutural da desconcentraçáo e da localização de aglomeração industriais, longamente estabelecido entre 1970 e 2015, não foi abalado de modo significativo pela recessão recente (até 2018). Contudo, a crise se expressou com mais contundência em territórios definidos por economias de aglomeração potentes (no sentido marshalliano), mas também por serem, simultaneamente, economias de diversificação (grandes e médios centros urbanos) produtiva (no sentido jacobsiano). Resistiram à crise sem perdas de empregos e até, às vezes, com pequenos ganhos, as aglomeraçóes de menor tamanho de emprego (entre 10 mil e 20 mil empregos industriais) em estados como Santa Catarina e Minas Gerais.

Por fim, o capítulo 12 apresenta as principais conclusóes do estudo e procura responder às inquirições sobre vetores territoriais consagradas na literatura. Intitulado Território e indústria no Brasil: revisitando o passado recente, mirando o futuro (conclusóes e apontamentos para políticas regionais), neste capítulo, desenvolvemos uma síntese dos principais marcos analíticos sugeridos pelo esforço de investigação. Ele foi elaborado para referir-se: i) ao debate das teses referenciais; ii) ao desenvolvimento analítico e seus principais resultados; iii) ao permanente exercício de política regional: a inspiração da União Europeia; e iv) aos aprendizados e desdobramentos futuros.

Os itens i e ii combinados organizam sínteses de resultados gerados na pesquisa. Invocam a hipótese da integração do mercado interno para apontar para a sua fragilização com a acelerada regressão produtiva em curso, ao mesmo tempo, que o vetor predominante, o de primarização do tecido econômico por meio da expansão das atividades ligadas a commodities agrominerais, expande territórios do emprego industrial sem romper com a força do campo aglomerativo do chamado "polígono da desconcentraçáo concentrada”. A desconcentração regional industrial continua a ocorrer, entretanto, seus efeitos nos novos territórios são de pouca monta, com baixa interligação setorial e inter-regional. As consequências deste "modelo" de crescimento de limitada potência estrutural passam a exigir a atualizaçáo do quadro das políticas - regionais ou não - produtivas, de infraestrutura e sociais (itens iii e iv). Requerem uma leitura multiescalar do território, em que a preocupação com a 
ativação econômico-produtiva deve ser combinada com a pluralidade de estágios de desenvolvimento observada em cada regiáo-alvo da política regional. A experiência europeia de política regional é sinalizada como uma referência essencial para o caso brasileiro. Esta ideia não é nova, entretanto, em tempos, como os atuais, de fortes restriçóes à ideia de política regional e de reaproximação com teses que advogam, para as políticas públicas, o objetivo máximo da busca da eficiência produtiva a qualquer custo, achamos oportuno trazer novas evidências sobre os desdobramentos e atualizaçôes de esforços da política regional no projeto político da União Europeia. Nesta, a política regional é vista como constitutiva das estratégias de desenvolvimento para um continente com menos disparidades territoriais que no Brasil e tem como horizonte de planejamento para a implementação de políticas o médio e longo prazo: não se espera que alteraçóes substanciais ocorram em um breve ciclo de planejamento. $\mathrm{O}$ tratamento escalar do território, no projeto europeu, tem avançado para mais e mais refinamento das necessidades e potencialidades de suas várias sub-regiōes, as quais, por sua vez, passam a demandar diferentes modelos de mudança estrutural.

Algumas conclusóes mais gerais do estudo podem ser rapidamente sumariadas aqui - conquanto esperamos, os autores, que os leitores tirem suas próprias conclusões - sobre o caráter recente do desenvolvimento brasileiro. Sem dúvida, a economia brasileira está passando por um grande momento de transformação, no qual sua capacidade de criar e/ou expandir setores e atividades econômicas de alto valor agregado e de competividade mundial está seriamente comprometida. Passada etapa histórica de constituição da mudança estrutural com base na internalização das atividades industriais, o momento agora nem é de expansão de novos setores de mais elevada produtividade (como o terciário moderno), nem de expansão das atividades industriais prevalecentes em direção a novo patamar tecnológico e de competitividade sistêmica.

Esse novo contexto de encaminhamento da atividade industrial tem como correspondência na questão regional uma desconcentração espúria, que se dá menos pela força expansiva de setores mais dinâmicos e mais pela busca de oportunidade, de setores em crise, em regióes com elevado crescimento econômico seja pelo impulso de seu setor externo (commodities agrominerais), seja pela expansão da renda interna provocada por políticas governamentais de expansão dos gastos sociais, do salário mínimo, de gastos em infraestrutura ou ainda derivadas de créditos públicos da política regional.

O padrão de ocupação territorial da indústria tem se revelado, não obstante mudanças identificadas, ainda com forte orientação de escolha nas regiōes Sudeste e Sul do país. O campo aglomerativo exercido pela economia destas duas regióes ainda se mostra relevante para a decisão de localização das plantas industriais de maior valor agregado $(\mathrm{VAB})$. 
Assim, como temos aprendido das experiências históricas europeias e mesmo americana (Estados Unidos), as economias de aglomeração que levam à excessiva concentração produtiva em um dado território nacional, uma vez instaladas são muito difíceis de serem revertidas. Contudo, os esforços governamentais para criar uma trajetória desconcentrada de desenvolvimento, desde o período do pós-Segunda Guerra (fim dos anos 1940), têm sido definitivos para o estabelecimento de forças para convergência econômica regional.

No Brasil, desde a década de 1970, nota-se que o processo de desconcentração produtiva está em curso, em alguns períodos com maior força e em outros mais fraco, mas sempre presente. O nosso estudo também veio confirmar a operosidade de tal tendência desconcentradora em termos regionais, ainda que em contexto adverso de armadilha do baixo crescimento do produto e da renda, bem como da mudança estrutural em caráter regressivo.

Este livro é fruto do plano de trabalho executado nos últimos quatro anos na Dirur do Ipea. Os pesquisadores, Raphael de Oliveira Silva e Danilo Severian, bolsistas do Subprograma de Pesquisa para o Desenvolvimento Nacional (PNPD), autores de capítulos integrantes do livro, tiveram papel crucial no desenvolvimento da pesquisa, no tratamento e na organizaçáo dos dados sobre a indústria brasileira. A presença e a motivação destes estudiosos foram determinantes para que também fizéssemos conjuntamente um exaustivo levantamento e uma leitura da literatura acadêmica considerada relevante para a pesquisa. Por conta da imersão deles na temática do desenvolvimento regional, conseguimos criar um ambiente de estímulo para o prosseguimento dos dois (um fluminense e outro paulista) em cursos de doutoramento com especialização em economia e desenvolvimento regional. Foram, sem dúvida, atraídos para uma nobre causa.

Vários admiráveis colegas de trabalho intelectual, relevantes pesquisadores nacionais sobre desenvolvimento regional, tiveram participação, direta ou indireta, nos resultados por nós elaborados. São estudiosos que vêm dando enorme contribuição ao Ipea e ao MDR para a atualização de diagnósticos sobre a questão regional brasileira: Carlos Antonio Brandão (Universidade Federal do Rio de Janeiro - UFRJ), Fernando Cezar de Macedo (Universidade Estadual de Campinas - Unicamp), Roberto do Carmo (Unicamp), Luciléia Aparecida Colombo (Universidade Federal de Alagoas - Ufal), Leonardo Porto (Unicamp), Kelly Camargo (Unicamp), Robson Silva (Universidade Federal Rural do Rio de Janeiro - UFRRJ), Murilo Pires (Dirur/Ipea), Daniel Sampaio (Universidade Federal do Espírito Santo - Ufes), Valdeci Monteiro dos Santos (Universidade Católica de Pernambuco - Unicap), Paulo Cavalcanti Filho (Universidade Federal da Paraíba - UFPB), Danilo Jorge Vieira (Universidade Federal de Minas Gerais UFMG), Mabel Diz Marques (Universidade Federal da Bahia - UFBA), colaboradora convidada em um dos capítulos do livro. Por fim, mas não por último, 
o estimado professor José Raimundo de Oliveira Vergolino, meu orientador no mestrado da Universidade Federal de Pernambuco (UFPE) anos atrás, com quem aprendi muito sobre teorias e modelos de crescimento regional.

Um agradecimento muito especial vai para Ana Cristina Fernandes (UFPE). Seu convite, ainda em 2018, para a colaboração na edição do dossiê temático Paradigmas técnico-econômicos e reconfiguração territorial, da Revista Brasileira de Estudos Urbanos e Regionais (RBEUR), lançada em maio de 2019, durante o evento da Associação Nacional de Pós-Graduação e Pesquisa em Planejamento Urbano e Regional (Anpur) em Natal (Rio Grande do Norte), foi muito estimulante para o desenvolvimento de várias das ideias especuladas em capítulos deste livro. A leitura, seleção e organização dos textos para a referida edição, com a parceria de Rovena Negreiros, permitiram, à época, o acesso a importantes e atuais estudos sobre transformaçôes territoriais no país.

Neste estudo travamos um diálogo constante e direto com duas teses fundamentais do debate regional brasileiro: a da "integração do mercado nacional", do professor Wilson Cano (in memorian), e a da "desconcentração concentrada", do professor Clélio Campolina Diniz. Wilson Cano foi meu orientador no doutorado da Unicamp e pessoa com quem esperava travar uma conversa e receber seus comentários sobre este material. Sua partida inesperada nos deixou frustrados, mas seus ensinamentos e referenciais analíticos estão aqui presentes. Quanto ao professor Campolina, sem dúvida, tê-lo por perto em debates de textos e na realização (por ele) de uma releitura e atualização de sua própria tese de vinte anos atrás sobre a "desconcentração concentrada", nesta fase final da pesquisa, permitiu o enriquecimento de facetas não observadas inicialmente sobre as transformaçóes territoriais brasileiras contemporâneas.

Um instigante e provocante parceiro invisível está em todos os capítulos: é o analista e gestor de políticas regionais. $\mathrm{O}$ material aqui abordado, conquanto suas digressôes teóricas remetidas a pesquisadores e estudiosos do desenvolvimento regional, tem um claro direcionamento para a reflexão da política regional brasileira. Esta preocupação se materializa pela presença constante de Adriana Melo Alves, Joáo Mendes da Rocha Neto e Vitarque Paes Coelho, todos especialistas em políticas públicas e gestão governamental no atual MDR (antigo Ministério da Integração Nacional).

O diálogo profícuo com estes gestores públicos sobre as limitaçôes e possibilidades da política regional (a Política Nacional de Desenvolvimento Regional PNDR) e dos seus instrumentos - e, é claro, suas demandas e orientaçóes ao plano de trabalho do Ipea - tem sido um norte para vários dos desdobramentos conceituais aqui presentes. $\mathrm{O}$ nosso reconhecimento de sua participação para o conteúdo deste livro é mais que merecido. 


\section{REFERÊNCIAS}

DINIZ, C. C. Desenvolvimento poligonal no Brasil: nem desconcentração, nem contínua polarização. Nova Economia, Belo Horizonte, v. 3, n. 1, p. 35-64, set. 1993. Disponível em: <https://bit.ly/3fYDLbP>.

DINIZ, C. C.; CROCCO, M. A. Reestruturação econômica e impacto regional: o novo mapa da indústria brasileira. Nova Economia, Belo Horizonte, v. 6, n. 1, p. 77-103, jul. 1996. Disponível em: <https://bit. ly/32g9pc4>.

Brasília, setembro de 2020

(Ano do centenário de nascimento de Celso Furtado) 